\title{
Smartphone-Based Healthcare Apps for Older Adults in the COVID-19 Era: Heuristic Evaluation
}

\author{
Hamid Reza SAEIDNIA ${ }^{\mathrm{a}, 1}$, Ali GHORBI ${ }^{\mathrm{b}}$, Marcin KOZAK ${ }^{\mathrm{c}}$ and Claudiu HERTELIU ${ }^{\mathrm{d}}$ \\ ${ }^{a}$ Department of Knowledge and Information Science, Tarbiat Modares University, \\ (TMU) Tehran, Iran \\ ${ }^{\mathrm{b}}$ Department of Knowledge and Information Science, Tehran University, Tehran, Iran \\ ${ }^{\mathrm{c}}$ Department of Media, Journalism and Social Communication, University of \\ Information Technology and Management, Rzeszow, Poland \\ ${ }^{\mathrm{d}}$ Department of Statistics and Econometrics, Bucharest University of Economic \\ Studies, 010552 Bucharest, Romania
}

\begin{abstract}
Many national governments have attempted to prevent and combat COVID-19 using mobile health (mHealth) technologies during the epidemic. During this time, governments began developing smartphone-based apps for prevention, call tracking, and monitoring people with COVID-19. An important question is, does everyone benefit from these technologies equally and fairly? To answer this question, we evaluated the user interface of smartphone-based apps developed during the COVID-19 era by considering their design for older adults, in order to determine whether social justice has been considered in the development of these apps.
\end{abstract}

Keywords. smartphone, user interface, healthcare, older adults, COVID-19

\section{Introduction}

In order to combat the coronavirus pandemic, governments and health organizations used mobile health (m-Health) technology in the areas of self-care, contact tracing, education, and others. In the meantime, smartphone-based apps have become a more noticeable presence, and many countries unveiled their own official apps. As these apps are used by all segments of society (e.g., older adults, the elderly, young people, and the physically disabled), all requirements related to the user interface must be considered. The ability for all users to benefit from software (including apps) is so crucial that it is considered a social justice [1] and human rights issue, in that its importance goes beyond software into human experience [2]. Numerous articles have shown that poor user interface design repels people from using software services $[2,3]$.

Therefore, in this study, we seek the answer to the question of whether social justice, in the user interface design of smartphone-based healthcare apps during the coronavirus,

\footnotetext{
${ }^{1}$ Corresponding Author, Hamid Reza Saeidnia, Department of knowledge and information science Tarbiat Modares University, (TMU) Tehran, Iran; E-mail: hamidrezasaednia@gmail.com.
} 
has been observed. For this purpose, we selected two apps from two countries considered to be developed and economically advantaged.

\section{Method}

This applied and descriptive research used the heuristic evaluation method. We examined the user interfaces of two official national apps in this study: COVID Alert and COVIDSafe. The former was developed by the Canadian government [4], and the COVIDSafe app by the Australian government [5]. We benefited from the experience of five IT experts to evaluate the user interfaces of these apps. These five experts have experience in app development and possess master's degrees or higher in health informatics, biomedical engineering, or health information technology disciplines (Table $1)$.

Table 1. Experts' qualifications.

\begin{tabular}{|c|c|c|c|c|c|}
\hline & Expert 1 (pilot) & Expert 2 & Expert 3 & Expert 4 & Expert 5 \\
\hline Sex & Male & Female & Male & Female & Male \\
\hline Age & 28 & 28 & 38 & 39 & 42 \\
\hline Education & $\begin{array}{l}\text { MSc (Engineering, } \\
\text { Information } \\
\text { Management) }\end{array}$ & $\begin{array}{l}\text { MSc (Health } \\
\text { Information } \\
\text { Management) }\end{array}$ & $\begin{array}{c}\mathrm{PhD} \\
\text { (Health } \\
\text { Informatics) }\end{array}$ & $\begin{array}{c}\mathrm{PhD} \\
\text { (Biomedical } \\
\text { Engineering) }\end{array}$ & $\begin{array}{c}\mathrm{PhD} \\
\text { (Health } \\
\text { Informatics) }\end{array}$ \\
\hline Profession & PhD fellow & $\mathrm{PhD}$ fellow & Professor & Professor & Professor \\
\hline
\end{tabular}

Each of the five experts spent two hours testing the apps. We used the recommendations of Morris (1994) [6] as a tool to analyze their user interfaces for older adults, which are basic principles of user interface design [7]. The recommendations included training in visual, auditory, physical, memory, attitudinal, and app training areas [6]. We provided these recommendations as a questionnaire including 44 items in 6 sections and asked the experts to rate their observations based on a 5-point severity ranking ( $1=$ Not at all, $2=$ Partially observed, 3=Fair, 4=Very good, 5=Excellent). We calculated that the questionnaire was reliable (Cronbach's alpha of 0.87), and five professors of health informatics and information management evaluated and confirmed the validity of the instrument. Each of the recommendations was considered as items properly adapted for older adults, if that item obtained an average of 3 or greater. Finally, a one-hour debriefing was held after the heuristic evaluation, during which the experts further commented on the apps. The data analysis was conducted using SPSS 22 software.

\section{Result}

The results of the heuristic evaluation indicate that, for both apps, most recommendations related to user interface design for older adults achieved a mean score under 3 . Table 2 shows the mean points for the recommendations.

Table 2. Average points of two selected apps

\begin{tabular}{llllll}
\hline Recommendations & $\begin{array}{c}\text { COVIDAlert } \\
\text { Ave. }\end{array}$ & $\begin{array}{c}\text { COVIDSafe } \\
\text { Ave. }\end{array}$ & Recommendations & $\begin{array}{c}\text { COVIDAlert } \\
\text { Ave. }\end{array}$ & $\begin{array}{c}\text { COVIDSafe } \\
\text { Ave. }\end{array}$ \\
\hline Visual & & & Memory & & \\
Font size & 3.2 & 3.2 & Visibility of objects & 2.4 & 2.2 \\
Text characteristics & 2.6 & 28 & Navigational aids & 2.2 & 2
\end{tabular}




\begin{tabular}{|c|c|c|c|c|c|}
\hline Resolution & 3.2 & 3.4 & Interaction style & 2.2 & 2.2 \\
\hline Lighting & 2.8 & 3.2 & $\begin{array}{ll}\begin{array}{l}\text { Design } \\
\text { consistency }\end{array} & \text { for }\end{array}$ & 1.8 & 2 \\
\hline Glare & 2.8 & 3 & Instructions & 2.2 & \\
\hline Color of text & 3.4 & 3.4 & Learning & 1 & 1 \\
\hline Brightness & 3.2 & 3.8 & Note-taking & 1 & 1 \\
\hline Object speed & 3 & 3 & Task structure & 2 & 2 \\
\hline Scrolling speed & 3.2 & 2.8 & $\begin{array}{l}\text { Information } \\
\text { presentation }\end{array}$ & 2.6 & 2.8 \\
\hline $\begin{array}{l}\text { Multiple sensory } \\
\text { modalities }\end{array}$ & 1.8 & 2.4 & User experience & 3 & 3 \\
\hline Interaction style & 2 & 2 & Attitudinal & & \\
\hline $\begin{array}{l}\text { Highly visually- } \\
\text { impaired users }\end{array}$ & 2 & 1.4 & $\begin{array}{l}\text { Designer } \\
\text { assumptions }\end{array}$ & 1 & 1 \\
\hline Auditory & & & System messages & 2.2 & 2 \\
\hline Arrangement & 3.2 & 3 & Wording & 2.4 & 2.2 \\
\hline Noise & 2 & 3 & Error-free design & 2 & 2 \\
\hline Task & 1.8 & 2.4 & $\begin{array}{l}\text { Notification of } \\
\text { interaction }\end{array}$ & 1 & 1 \\
\hline Frequencies & 2.2 & 2.6 & App training & & \\
\hline Synthesized & 2.4 & 3.4 & Written materials & 1.8 & 2 \\
\hline Dimensions & 2.6 & 4 & $\begin{array}{l}\text { Training session } \\
\text { length }\end{array}$ & 1 & 1 \\
\hline $\begin{array}{l}\text { Highly hearing- } \\
\text { impaired users }\end{array}$ & 2 & 2 & Self-pacing & 1 & 1 \\
\hline Physical & & & Help & 2 & 2 \\
\hline Menu structure & 1.6 & 2 & $\begin{array}{l}\text { Instructional } \\
\text { technique }\end{array}$ & 1 & 1 \\
\hline Documentation & 1.8 & 2 & Training strategy & 1 & 1 \\
\hline Experienced typists & 2 & 1.8 & & & \\
\hline
\end{tabular}

\section{Discussion}

In this study, we examined the user interface of two official government apps developed during the coronavirus. By this, we aimed to answer the question of whether the user interface design of these two apps considered the issue of accessibility for older adults.

According to the findings of the heuristic evaluation, these two apps did not apply any of the fundamental design principles well, except for a few items that should be considered as general, basic recommendations for older adults. For the items font size, resolution, text color, and brightness, both apps averaged 3 or above, which can be described as good. For a limited number of the other items, the COVIDSafe app averaged higher than the COVIDAlert app.

Both apps had the lowest average scores in most other items, such as interaction style, hearing-impaired access, learning, note-taking, designer assumptions, notification of interaction, training session length, self-pacing, help, instructional technique, and training strategy. Over half of the 44 items used to design user interfaces for older adults in both apps did not comply with the recommendations. However, older adults are among the most vulnerable people to the coronavirus [8], and so, certainly, these people should have been given more attention while developing these apps. Based on a report by the World Health Organization, during the next 40 years (until 2060), 29.7\% of the worldwide population is projected to be older adults [9]. This illustrates the importance of addressing this huge and growing segment of the population. What is apparent at the moment is the lack of attention in app development for this group at the national level, and for design in general. 
After the heuristic evaluation in the debriefing, the experts agreed that in addition to the complex user interface, other essential aspects of these apps, such as connecting to the Internet at least once a day and Bluetooth or Wi-Fi support, were difficult and often incomprehensible to older adults. This issue - that the technology required to help older adults often is not understood-is referred to as the "elderly paradox" [10]. Numerous studies have emphasized the importance of user interface design and user experience for all community members to benefit from healthcare apps in the coronavirus era $[11,12]$. This is because these coronavirus apps must be downloaded by a majority of users to be effective [10].

Among the study's limitations, there was the absence of a standardized tool or questionnaire (e.g., SUS) for review of user interface design apps aimed at older adults. We compensated for this limitation by using fundamental recommendations for user interface design. Another limitation was the number of apps studied-only two. In order to evaluate the user interfaces designed for older adults during the coronavirus, more apps should be analyzed. Future research can address this issue.

\section{Conclusions}

In designing and developing healthcare apps that are implemented nationally, it is crucial to pay attention to the design of the user interface for older adults or groups with physical disabilities (e.g., hearing or vision). In these circumstances, either a separate version should be developed for these people, or features should be included in the app that allow easy use by older adults or people with physical disabilities. This work is partially supported by a grant from the Romanian National Authority for Scientific Research and Innovation, CNDS-UEFISCDI, project number PN-III-P4-ID-PCCF-2016-0084.

\section{References}

[1] Costanza-Chock S. Design Justice and User Interface Design. Proceedings of the 33rd Annual ACM Symposium on User Interface Software and Technology; 2020.

[2] Harihareswara S. User experience is a social justice issue. Code4Lib Journal. 2015(28).

[3] Walls DM. User experience in social justice contexts. Proceedings of the 34th ACM International Conference on the Design of Communication; 2016.

[4] COVID Alert today 2020. Available at: https://www.canada.ca/en/publichealth/services/diseases/coronavirus-disease-covid-19/covid-alert.html.

[5] COVIDSafe app 2020. Available at: https://www.health.gov.au/resources/apps-and-tools/covidsafe-app.

[6] Morris JM. User interface design for older adults. Interacting with Computers. 1994;6(4):373-93.

[7] Wagner N, Hassanein K, Head M. Computer use by older adults: A multi-disciplinary review. Computers in human behavior. 2010;26(5):870-82.

[8] Shahid Z, Kalayanamitra R, McClafferty B, Kepko D, Ramgobin D, Patel R, et al. COVID-19 and older adults: what we know. Journal of the American Geriatrics Society. 2020;68(5):926-9.

[9] Mattiuzzi C, Lippi G. Worldwide disease epidemiology in the older persons. European geriatric medicine. 2020;11(1):147-53.

[10] Rizzo E. COVID-19 contact tracing apps: the 'elderly paradox'. Public health. 2020;185:127.

[11] Saeidnia H, Mohammadzadeh Z, Saeidnia M, Mahmoodzadeh A, Ghorbani N, Hasanzadeh M. Identifying Requirements of a Self-care System on smartphones for preventing coronavirus disease 2019 (COVID-19). Iranian Journal of Medical Microbiology. 2020;14(3):241-6.

[12] Saeidnia HR, Mohammadzadeh Z, Hassanzadeh M. Evaluation of Mobile Phone Healthcare Applications During the Covid-19 Pandemic. Studies in health technology and informatics. 2021;281:1100-1. 